\title{
Overexpression of a PIP1 Gene from Salicornia bigelovii in Tobacco Plants Improves Their Drought Tolerance
}

\author{
Xiaobo Sun, Yanming Deng, Lijian Liang, Xinping Jia, Zheng Xiao, and Jiale Su${ }^{1}$ \\ Institute of Leisure Agriculture, Jiangsu Key Laboratory for Horticultural Crop Genetic Improvement, \\ Jiangsu Academy of Agricultural Sciences, Nanjing 210014, Jiangsu, China
}

\begin{abstract}
AdDitional INDEX wORDs. aquaporin, quantitative real-time PCR, subcellular localization, transgenic tobacco
Abstract. Aquaporin (AQP) proteins can transport water and other small molecules through cellular membranes and are one of the first targets of stress-induced signaling in plants. A number of $A Q P$ genes have been identified from glycophytes, and their functions have been studied. However, the reports on $A Q P$ s from halophytes and their precise role in abiotic stress response are still rare. In this study, we have identified a $P I P 1$ subgroup $A Q P$ gene, designated $S b P I P 1$, from the euhalophyte Salicornia bigelovii and characterized it by overexpressing in tobacco plants. SbPIP1 transcript was induced by cold, but suppressed by $\mathrm{NaCl}$ and polyethylene glycol (PEG). Transient expression of GFP (green fluorescent protein)-SbPIP fusion protein indicated its localization in the plasma membrane. Overexpression of $S b P I P 1$ in tobacco (Nicotiana tabacum) plants increased their drought tolerance. Leaf protoplasts from transgenic tobacco plants absorbed water more quickly than those from wild type (WT) plants when they were put into hypotonic solution. In addition, the transgenic tobacco plants possessed higher relative water content (RWC) and proline content, but lower levels of malondialdehyde (MDA) and less ion leakage (IL) when compared with WT under the treatment of the different concentrations of PEG. Taken together, our results demonstrate that heterologous expression of $S b P I P 1$ in tobacco plants confers them drought stress tolerance by reducing membrane injury and increasing the ability to retain water.
\end{abstract}

Plant survival, growth, and development depend on water absorption from the soil and transport from the roots to other plant parts (Aharon et al., 2003). In plants, water movement is controlled by both apoplastic and symplastic pathways (Alexandersson et al., 2010; Luu and Maurel, 2005). The latter is more efficient in regulating water transport across membranes when plants are experiencing abiotic stresses (Lian et al., 2004; Vera-Estrella et al., 2004). The symplastic pathway is regulated mainly by the members of $\mathrm{AQP}$ proteins (Amodeo et al., 1999). AQPs belong to a highly conserved group of the major intrinsic protein (MIP) family and are localized in the plasma membrane, the tonoplast, or in other cell membranes (Kaldenhoff and Fischer, 2006). They facilitate the transport of not only water but also other small neutral molecules and gases through biological membranes (Chaumont and Tyerman, 2014; Kaldenhoff and Fischer, 2006; Sade et al., 2010). Since the first $A Q P$ gene was isolated from Arabidopsis thaliana (Maurel et al., 1993), a number of $A Q P$ genes have been identified from glycophytes, including 35 from $A$. thaliana (Johanson et al., 2001), 36 from maize Zea mays (Chaumont et al., 2001), 33 from rice Oryza sativa (Sakurai et al., 2005), 65 from Populus trichocarpa (Gupta and Sankararamakrishnan, 2009), and 71 from Gossypium hirsutum (Park et al., 2010). However, there have been few reports about $A Q P S$ in halophytes up to now (Chang et al., 2016; Li et al., 2015). These $A Q P$ genes encode various $\mathrm{AQP}$ isoforms and can be classified into five different subfamilies named plasma membrane intrinsic proteins (PIPs), tonoplast intrinsic proteins (TIPs), NOD 26-like intrinsic

Received for publication 8 Mar. 2017. Accepted for publication 28 Apr. 2017. This research was supported by the Chinese Science and Technology Supporting Program (grant No. 2013BAD01B070403).

${ }^{1}$ Corresponding author. E-mail: suj166@aliyun.com. proteins (NIPs), small basic intrinsic proteins (SIPs), and uncharacterized intrinsic proteins (XIPs) according to subcellular localization and sequence similarity (Johanson et al., 2001; Lopez et al., 2012; Sade et al., 2009). These various AQPs are involved in diverse physiological processes of plants, including seed germination, cell elongation, stomata movement, phloem loading and unloading, reproductive growth, and stress responses (Eisenbarth and Weig, 2005; Forrest and Bhave, 2007; Gao et al., 2010; Lian et al., 2004). Previous studies have shown that environmental stresses such as cold, drought, and salt can lead to water loss of plants (Parent et al., 2009; Wang, 2010). $A Q P$ s are closely related to stress tolerance and are one of the first targets of the stress-induced signaling in plants (Rae et al., 2011; Santos and Mazzafera, 2013). As an important constituent of several stress response pathways, the role of $A Q P$ s to confer plants tolerance to abiotic stresses has been demonstrated by transgenic approaches (Cui et al., 2008; Hu et al., 2012; Peng et al., 2008; Zhou et al., 2012). Therefore, the $A Q P$ s that are able to endow improved tolerance under abiotic stresses are valuable gene resources in genetic engineering of crops for stress tolerance.

Salicornia bigelovii is a succulent marine halophyte belonging to the Chenopodiaceae. It has been consumed not only as a popular kind of vegetable but also as a medicinal plant to treat hypertension, cephalalgia, scurvy, and cancer (Feng and Weng, 2009; Guan et al., 2015; Lu et al., 2001; Wang et al., 2012). As a typical euhalophyte, S. bigelovii not only tolerates high concentration of $\mathrm{Na}^{+}$but also requires $300 \mathrm{mmol} \cdot \mathrm{L}^{-1} \mathrm{NaCl}$ for optimal growth (Ayala and O'leary, 1995; Wang and Zhao, 2004). In contrast to some other halophytic plants, S. bigelovii does not exclude $\mathrm{Na}^{+}$or sequester it within specialized structures such as salt glands and so on, and not significantly accumulated organic osmolytes in response to salt (Wang and 
Zhao, 2004; Zhao et al., 2013). Therefore, S. bigelovii has an excellent gene pool for studying tolerance mechanism of plants to salt and osmotic stresses. Though a great deal is known about $A Q P$ s in a wide variety of plant genera and species, very little has been learned about the molecular basis of water transport in $S$. bigelovii, and no $A Q P$ s have been identified from $S$. bigelovii up to now. Cloning and studying of $A Q P$ s from $S$. bigelovii will not only contribute to the understanding of moisture balance mechanism in cells and tissues of $S$. bigelovii under osmotic stress caused by high salt but also can provide gene resources for the improvement of drought and salt tolerance in glycophytic crop species.

The objectives of this work were to isolate the cDNA full length of a putative $A Q P$ gene, $S b P I P 1$, from $S$. bigelovii, detect its expression changes in $S$. bigelovii under abiotic stresses, and examine the cellular localization of the SbPIP1 protein in onion epidermal cells. Because the physiological responses of SbPIP1-overexpressing wheat (Triticum aestivum) with salt stress have been reported by $\mathrm{Yu}$ et al. (2015), we also investigated the drought tolerance and physiological responses of SbPIP1-overexpressing tobacco to further understand the physiological functions mediated by $S b P I P 1$ in plants.

\section{Materials and Methods}

Plant materials and treatments. Salicornia bigelovii seeds were soaked in tap water for $3 \mathrm{~h}$ and then grown in plastic pots $(1.2 \mathrm{~L})$ containing sand and watered daily with $1 / 2$ Hoagland nutrient solution according to Wan and Zhao (2004). After the seeds germinated, all plants were cultured in a climatic cabinet under a light intensity of $600 \mu \mathrm{mol} \cdot \mathrm{m}^{-2} \cdot \mathrm{s}^{-1}$ during a $15 / 9 \mathrm{~h}$ light/dark cycle at $20^{\circ} \mathrm{C} / 30^{\circ} \mathrm{C}$. For stress treatments, 60 -d-old seedlings with uniform growth were removed from sand carefully and transferred in $1 / 2$ Hoagland nutrient solution containing 20\% PEG 6000 (dehydration stress) and 600 $\mathrm{mmol} \cdot \mathrm{L}^{-1} \mathrm{NaCl}$ (salinity stress), respectively, for various periods of time, including time points 0 (normal growth conditions without stress), $0.5,2,4,8,12$, and $24 \mathrm{~h}$. For lowtemperature treatment, potted seedlings were put in a growth chamber at $4{ }^{\circ} \mathrm{C}$ for 0 (normal growth conditions without stress), $0.5,2,4,8,12$, and $24 \mathrm{~h}$, respectively. Excised roots and succulent stems from treated or control plants were subsequently frozen in liquid nitrogen and stored at $-80{ }^{\circ} \mathrm{C}$ for extraction of total RNA and real-time quantitative polymerase chain reaction (qRT-PCR) assay.

Cloning ANd Sequence analysis of $\boldsymbol{S}_{\boldsymbol{B}} \boldsymbol{P I P 1}$. A suppressionsubtract-hybridization cDNA library of salt stress from $S$. bigelovii was constructed by our laboratory, and a putative AQP gene fragment (GeneBank accession no. DY530090) was cloned, which contained an incomplete open reading frame (ORF) lacking the nucleotide sequence of 3' terminal. Employing rapid amplification of cDNA ends (RACE), the $3^{\prime}$ end of the gene was amplified with the GeneRacer Kit (Invitrogen, Carlsbad, CA) using two gene-specific nested primers SbPF: 5'-GGTGACGGTCTCGGTGCTGA-3' and SbPF1: 5' GTTCTCGTCTACACCGTCTTCTC- $3^{\prime}$ as primers and cDNA obtained from succulent stems of $S$. bigelovii seedlings as templates. The amplified products of the $3^{\prime}$ cDNA ends were purified and inserted into the pMD18-T vector (TaKaRa, Dalian, China) and sequenced (Sangon, Shanghai, China). The full-length cDNA sequence was obtained by combining the known gene fragment and the $3^{\prime}$ end sequence with an overlap fragment using DNAMAN 5.0 (Lynnon Corp., Vaudreuil, QC, Canada) and was amplified by reverse transcriptasepolymerase chain reaction (RT-PCR) with the primers SbPIP1F: 5' -CCTACACAAAACAACACTCACTC-3' and SbPIP1R: 5'-CATTTCCACACCCAGTGCAGACC-3'. The amplified sequence was subcloned into the pMD18-T vector, sequenced, and submitted to GenBank.

The ORF of SbPIPI and the properties of protein encoded by it were predicted by DNASTAR software (DNASTAR, Madison, WI). Subcellular localization of SbPIP1 was predicted using the online tool WoLF PSORT (Horton et al., 2007). The signal peptide sequence and the transmembrane region of the SbPIP1 protein can be detected using SignalP 3.0 Server (Bendtsen et al., 2004) and TMpred Server (Hofmann, 1993), respectively. Homologous sequences and conserved domain can be searched through the NCBI BLAST (National Center for Biotechnology Information, Bethesda, MD). Multiple sequence alignment was performed employing Clustalx 2.1 (Larkin et al., 2007) and GeneDoc (Nicholas et al., 1997). The maximum likelihood (ML) tree from the aligned SbPIP1 and other plant MIPs was constructed using Clustalx 2.1 and MEGA 5.1 (Tamura et al., 2011) to explore their evolutionary relationships. Structural homology modeling of SbPIP1 was generated in SWISS-MODEL (Biasini et al., 2014), and typical tetrameric quaternary structures were modeled with SbPIP1 based on the molecular model of SoPIP2;1 (PDB ID: 1z98.1.A).

GENE EXPRESSION ANALYSIS BY QRT-PCR. Expression of SbPIP1 in roots and succulent stems of $S$. bigelovii after different treatments was evaluated by qRT-PCR using the fluorescent intercalating dye SYBR Green Supermix (TaKaRa) on a Roche LightCycler 2.0 instrument (Roche, Basel, Switzerland). Total RNA was extracted from harvested samples using plant RNA extraction kits (Promega, Madison, WI), and the contaminant DNA has been removed with DNase I in the RNA extraction process. Each $2 \mu \mathrm{g}$ of total RNA was converted into cDNA using PrimeScript RT reagent Kit (TaKaRa). The SbPIP1 primers used in the qRT-PCR analysis (forward $5^{\prime}$ TGATGGATGATAAATTAATATG-3', reverse 5'-AACAA CCСТCTCAGGATTCTTC- $3^{\prime}$ ) were designed using Oligo 7.0 program (MBI, Cascade, $\mathrm{CO}$ ), which were located in $3^{\prime}$ untranslated region and excluded the highly conserved protein domain. The primers had high efficiency and specificity based on agarose gel electrophoresis and melting curve analysis. To confirm the specificity of primer pairs, PCR products were subsequently subjected to sequence analysis. A series of template and primer dilutions were tested to determine the optimal template and primer concentration for maximum amplification of the target during the experiments before proceeding with the actual experiments. In all experiments, appropriate negative controls containing no template were subjected to the same procedure to exclude or detect any possible contamination. The $S$. bigelovii Actin gene was used as an internal control gene for data normalization and calculating the relative mRNA levels, and the primers used in qRT-PCR were 5'-TTTGAGCAGGAATCAGAAACCGCC-3' and 5'-AGGACCTCTGGGCAACGGAATCTC-3'. The mRNA fold difference was relative to that of untreated samples used as calibrator. The relative expression level of genes was calculated using the $2^{-\Delta \Delta \mathrm{Ct}}$ formula (Livak and Schmittgen, 2001).

Subcellular localization of SbPIP1 Protein. The coding sequence of SbPIPl was amplified by PCR using primers 
SbOF1: 5' -CCCAAATCCAATGGAAGGAAAGGAGGAA GATGTA-3' and SbOF2: 5'-TCACTTGGATTTAAATGG GATTGC-3' and was combined with green fluorescent protein of pX-DG-vector (Chen et al., 2009) to yield a fusion protein GFP-SbPIP1. Next, the fusion expression vector $\mathrm{pX}-\mathrm{DG}$ SbPIP1 was introduced into onion epidermal cells using a gene gun (PDS-1000; Bio-Rad, Hercules, CA) for transient expression, as previously described by Chen et al. (2002). The plasmid pX-DG-vector containing the GFP ORF under the control of constitutive Cauliflower mosaic virus (CaMV) 35S promoter was used as the negative control. After the bombarded epidermal peels of onion were incubated on Murashige and Skoog (MS) medium at $25{ }^{\circ} \mathrm{C}$ for $16-24 \mathrm{~h}$ in the dark, GFP fluorescence in the onion epidermal cells was visualized under a laser confocal scanning microscope (LSM 510; Zeiss, Oberkochen, Germany) at a wavelength of $488 \mathrm{~nm}$.

Plasmid construction, plant transformation, and IDENTIFICATION OF TRANSGENiC Plants. The coding sequence of SbPIPl containing the BamHI/SacI restriction site, respectively, was amplified by using primers (SbOF3: 5' GCCGGATCCATGGAAGGAAAGGAGGAAGATG-3' and SbOF4: 5' - GCCGAGCTCTCACTTGGATTTAAATGG GATTGC- $\left.3^{\prime}\right)$. The PCR products were subcloned into
BamHI/SacI sites of pCAMBIA2301 expression vector under control of the CaMV $35 \mathrm{~S}$ promoter, and overexpression construct pCAMBIA2301-SbPIP1 was obtained. The recombinant plasmid was introduced into the Agrobacterium tumefaciens strain EHA105. The transgenic tobaccos were generated using A. tumefaciens-mediated transformation method (Horsch et al., 1985). Callus induction, shoot differentiation, and regeneration were selected on MS medium containing 200 $\mathrm{mg} \cdot \mathrm{L}^{-1}$ kanamycin $(\mathrm{Km})$. The $\mathrm{T}_{0} \mathrm{Km}$-resistant seedlings were further screened by PCR amplification with the combination of the CaMV $35 \mathrm{~S}$ promoter forward primer $35 \mathrm{SF}$ : $5^{\prime}$ CCTTTGGTCTTCTGAGACTGTATC-3' and SbPIP1-specific reverse primer SbOF4.

The seeds from $\mathrm{T}_{0}$ transgenic plants were selected on MS medium containing $200 \mathrm{mg} \cdot \mathrm{L}^{-1} \mathrm{Km}$. The $\mathrm{T}_{1} \mathrm{Km}$-resistant seedlings were confirmed by RT-PCR amplification using the primers SbOF3 and SbOF4. Two independent transgenic $\mathrm{T}_{2}$ line seedlings (Y6 and Y8) that almost all survived on MS medium containing $200 \mathrm{mg} \cdot \mathrm{L}^{-1} \mathrm{Km}$ were used in the following experiments. The expression of SbPIP1 in the two independent $\mathrm{T}_{2}$ lines was investigated by using semiquantitative RT-PCR analysis with SbOF3 and SbOF4 as primers and Actin as an internal control gene.

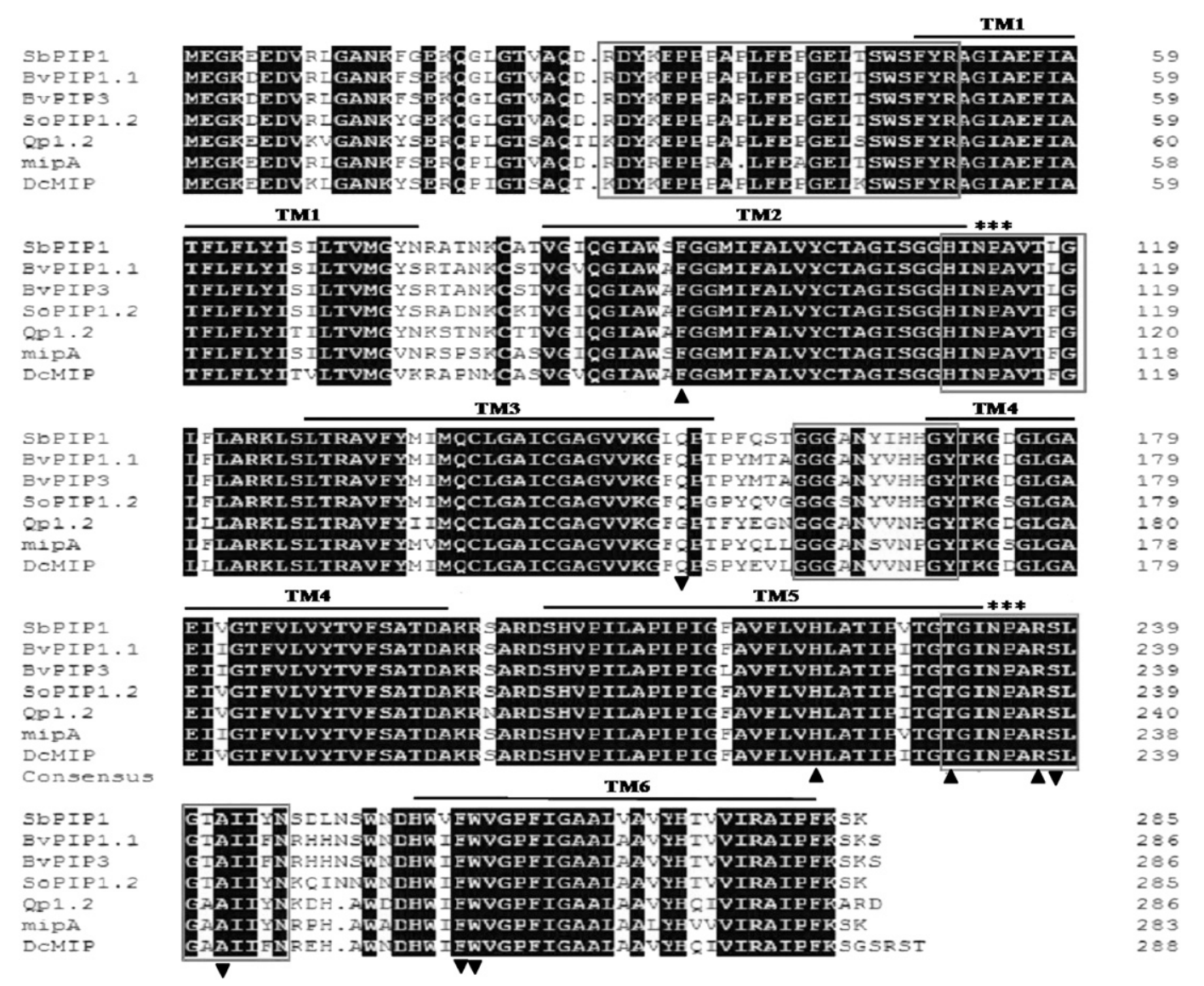

Fig. 1. Comparison of the deduced amino acid sequences of Salicornia bigelovii SbPIP1 with homologs from six other plants, including BvPIP1.1 (ACT22629.1) and BvPIP3 (AAB67870.1) from Beta vulgaris, SoPIP1.2 (AAR23268.1) from Spinacia oleracea, QpPIP1.2 (AFH36340.1) from Quercus petraea, mipA (AAB09747.1) from Mesembryanthemum crystallinum, and DcPIP (BAI94500.1) from Dianthus caryophyllus. The sequences were aligned using Clustalx 2.1 (Larkin et al., 2007) and GeneDoc (Nicholas et al., 1997) software. Amino acid numbers are shown on the right. The six putative transmembrane domains (TM1TM6) are denoted by lines above. The two conserved amino acid sequence present in major intrinsic protein and two typical signal consensus sequences of plasma membrane were boxed. The NPA motifs were indicated by asterisks. Triangles indicate the Ar/R selectivity filter and inverted triangles Froger's position, respectively. 
Drought tolerance assays of the WT AND the TRANSGENIC PLANTS. For drought stress tolerance assay, tobacco seedlings of four-leaf stage from WT, Y6, and Y8 lines were removed from soil and transplanted in $1 / 2$ Hoagland nutrient solution under a $16 / 8 \mathrm{~h}$ light/dark cycle at $25^{\circ} \mathrm{C}$ for $10 \mathrm{~d}$, and then the seedlings with consistent growth state were transferred into $1 / 2$ Hoagland nutrient solution containing 20\% PEG 6000. After $3 \mathrm{~d}$ drought stress-simulating treatment, photographs of the seedlings were taken. In addition, the untreated four-leaf stage tobacco seedlings from WT and Y8 line were transplanted in containers filled with a mixture of soil and sand (3:1) where they were regularly watered with $400 \mathrm{~mL}$ tap water per $2 \mathrm{~d}$ for 1 month, then watering was withheld to test their drought stress tolerance. The degree of wilting was observed over a period of $10 \mathrm{~d}$ and photographs were taken.

Preparation OF TOBACCO LEAF PROTOPLASTS AND STABILITY ASSAY IN HYPOTONIC SOLUTION. Protoplasts from leaves of transgenic and nontransgenic tobacco plants were isolated as described by Maliga et al. (1995) and observed under a light microscope. Then, the tobacco leaf protoplasts were resuspended with W5 solution (154 mM NaCl, $125 \mathrm{~mm} \mathrm{CaCl}_{2}, 5 \mathrm{~mm}$ $\mathrm{KCl}, 5 \mathrm{~mm}$ Glucose, $\mathrm{pH} 5.8)$ and stored at $4{ }^{\circ} \mathrm{C}$ for assay $(\mathrm{Yu}$ et al., 2005). Hypotonic solution was prepared by diluting one volume of W5 solution with two volumes of distilled water. $150 \mu \mathrm{L}$ hypotonic solution and $15 \mu \mathrm{L}$ protoplasts were taken and mixed on a glass slide. The process of protoplast burst at lower osmotic pressure was observed under a light microscope, and photographs were taken by a digital camera.

Measurement of RWC, IL, MDA, AND Proline Content. Tobacco seedlings of four-leaf stage from WT and Y8 line were transplanted in 1/2 Hoagland nutrient solution under a $16 / 8 \mathrm{~h}$ light/dark cycle at $25^{\circ} \mathrm{C}$ for $10 \mathrm{~d}$, then the seedlings with consistent growth state were transferred into 1/2 Hoagland nutrient solution containing $0,4 \%, 8 \%, 12 \%, 16 \%$, and $20 \%$ PEG 6000, respectively, to simulate dehydration stress with different degrees. After treatment for $36 \mathrm{~h}$, the plants were collected to measure RWC, IL, MDA, and proline contents. For the RWC assay, tobacco leaves from WT and Y8 line were sampled and weighed immediately [fresh weight $(\mathrm{FW})$ ], and then the leaves were soaked in distilled water for $24 \mathrm{~h}$ at $4{ }^{\circ} \mathrm{C}$ in the dark, and the turgid weight (TW) was recorded. After drying for $48 \mathrm{~h}$ at $80^{\circ} \mathrm{C}$, total dry weight (DW) was recorded. RWC was calculated as follows: RWC (percent $)=[(\mathrm{FW}-\mathrm{DW}) /$ $(\mathrm{TW}-\mathrm{DW})] \times 100$ (Barrs and Weatherley, 1962). IL was detected according to the method described by Jiang and Zhang (2001). The collected tobacco leaves were cut into strips and incubated in $10 \mathrm{~mL}$ of distilled water at $25{ }^{\circ} \mathrm{C}$ for $10 \mathrm{~h}$, and the initial conductivity (C1) was measured with a conductivity meter (DDBJ-350; INESA Scientific instrument Co., Shanghai, China). The leaves were then boiled for $10 \mathrm{~min}$ to yield complete IL. After cooling down, the electrolyte conductivity (C2) was measured. IL was calculated as follows: IL $(\%)=\mathrm{C} 1 /$ $\mathrm{C} 2 \times 100$. MDA content was determined by the thiobarbituric acid-based colorimetric method as described by Heath and Packer (1968). Proline content was determined by the ninhydrinbased colorimetric method as described by Irigoyen et al. (1992).

Statistical analysis. All the experiments were conducted separately using a completely randomized design with three replicates per treatment. Levels of gene expression were analyzed with analysis of variance using a repeated measurements model. Mean fold change of transcript levels was transformed to a logarithmic scale ( $\log 2)$ for statistical analysis. Drought physiological data were analyzed using $t$ tests. Significant differences among means were determined by least significant difference at $P<0.05$ or $P<0.01$. All Statistical analyses were performed using SPSS software (version 13.0; IBM Corp., Armonk, NY).

\section{Results and Discussion}

SBPIP1 ENCOdes A PIP1 Subgroup OF AQP IN $S$. BIGELOVII. The full-length cDNA sequence of a putative AQP gene, designated as SbPIP1 (GenBank accession no. DQ451602), was cloned by RACE. SbPIPl cDNA is 1107 bp and contains an 858-bp ORF that encodes 285 amino acid residues. The deduced SbPIP1 protein possesses a theoretical molecular mass of $30.5 \mathrm{kDa}$ and an isoelectric point of 8.66. Blastp analysis revealed that SbPIP1 shared high similarity with known PIP protein and contained six putative transmembrane $\alpha$-helices and two highly conserved Asn-Pro-Ala (NPA) motifs (Fig. 1). SbPIP1 contained the conserved sequences 'HINPAVTLG' and $(\mathrm{R} / \mathrm{K}) \mathrm{DYX}(\mathrm{E} / \mathrm{D}) \mathrm{PP}(\mathrm{P} / \mathrm{R}) \mathrm{X}_{3-4}(\mathrm{E} / \mathrm{D}) \mathrm{XXELXXWSF}(\mathrm{Y} / \mathrm{W}) \mathrm{R}$, which are present in all PIP members, and two typical signal consensus sequences of plasma membrane 'GGGANXXXXGY' and 'TGI/TNPARSL/FGTAI/Vl/VF/YN' (Fig. 1). Based on the sequence homology of isoforms, the PIP subfamily can be divided into two groups: PIP1 and PIP2 (Schaffner, 1998), and AQPs from each PIP subgroup can act individually in a different manner (Zelazny et al., 2009), or may interact together as a heterodimer to facilitate subcellular trafficking toward the plasma membrane (Fetter et al., 2004; Zelazny et al., 2007). SbPIP1 bears a longer amino-terminal extension compared with the PIP2 proteins, which is in line with the description for PIP1 proteins by Chaumont et al. (2000). The Ar/R selectivity

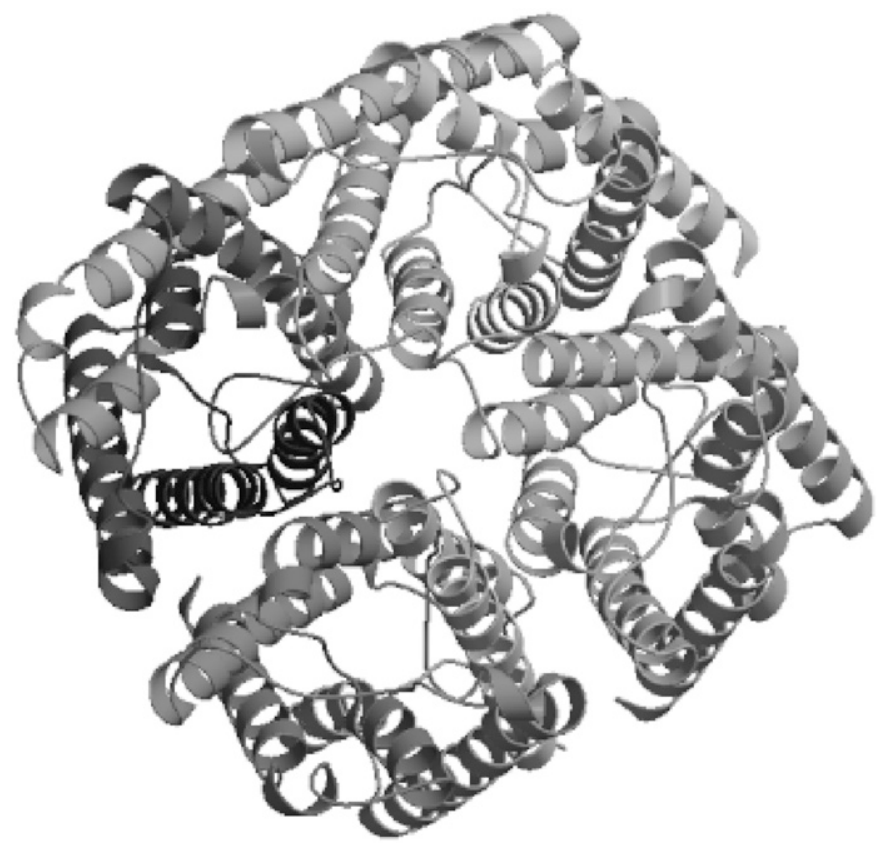

Fig. 2. Homology modeling of SbPIP1. Structural homology models were generated in SWISS-MODEL (Biasini et al., 2014). Typical tetrameric quaternary structures were modeled with SbPIP1 based on the molecular model of SoPIP2;1 (PDB ID: 1z98.1.A). 
filter (H2, H5, LE1, and LE2) and Froger's position (P1- P5) were also conserved in SbPIP1 (Fig. 1). Typical tetrameric quaternary structures were modeled with SbPIP1 based on the molecular model of SoPIP2;1 (PDB ID: 1z98.1.A) (Fig. 2).

Through blastp homology search, a multiple sequence alignment was conducted with SbPIP1 and six homologous PIP proteins from other plants, including BvPIP1.1 (ACT22629.1) and BvPIP3 (AAB67870.1) from Beta vulgaris, SoPIP1.2 (AAR23268.1) from Spinacia oleracea, QpPIP1.2 (AFH36340.1) from Quercus petraea, mipA (AAB09747.1) from Mesembryanthemum crystallinum, and DcPIP (BAI94500.1) from Dianthus caryophyllus (Fig. 1). SbPIP protein shares $92.3 \%, 92.0 \%, 92.0 \%, 87.4 \%, 85.0 \%$, and $83.1 \%$ amino acid sequence identity with SoPIP1.2, BvPIP1.1, BvMIP3, mipA, QpPIP1.2, and DcMI, respectively. Based on the amino acid sequence alignment, a phylogenetic tree of the AQPs between SbPIP1 and other plant AQPs obtained from GenBank were constructed (Fig. 3). This result showed that on an evolutionary timescale, SbPIP1 was grouped into the big branch of PIP1-type proteins and had a relatively close evolutionary relationship with the PIP1s from Chenopodiaceae plants $B$. vulgaris and $S$. oleracea.

$S_{B} P I P 1$ is downRegulated IN Response to $\mathrm{N}_{A} \mathrm{Cl}_{\mathrm{L}}$ ANd PEG TREATMENTS BUT UPREGULATED TO COLD. Many studies have

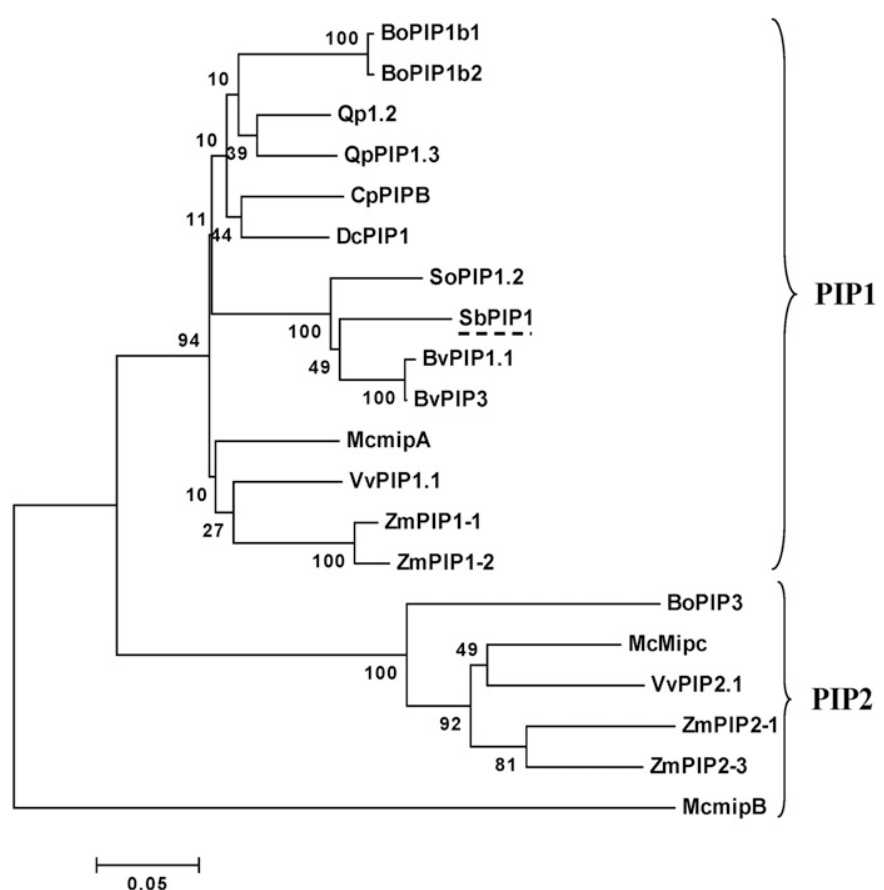

Fig. 3. Phylogenetic tree of SbPIP1 protein from Salicornia bigelovii and other plant AQPs. Multiple sequence alignments and the phylogenetic analyses were conducted with Clustalx 2.1 (Larkin et al., 2007) and MEGA 5.1 (Tamura et al., 2011). The scale bar indicates branch lengths. The species and GenBank accession numbers of the sequences are as follows: $S$. bigelovii SbPIP1 (DQ451602); Beta vulgaris BvPIP1.1 (ACT226291) and BvPIP3 (AAB67870); Spinacia oleracea SoPIP1.2 (AAR23268); Quercus petraea QpPIP1.2 (AFH36340) and QpPIP1.3 (AFH36341); Mesembryanthemum crystallinum McmipA (AAB09747), McmipB (AAA93521), and McMipC (AAB18227); Dianthus caryophyllus DcPIP1 (BAI94500); Brassica oleracea BoPIP1b1 (AAG23179), BoPIP1b2 (AAG23180), and BoPIP3 (AAG30607); Zea mays ZmPIP1-1 (AAO86706), ZmPIP1-2 (NP_001104934), ZmPIP2-1 (AAK26758), and ZmPIP2-3 (AAK26760); and Vitis vinifera VvPIP1.1 (NP_001267918) and VvPIP2.1 (AAV69744).
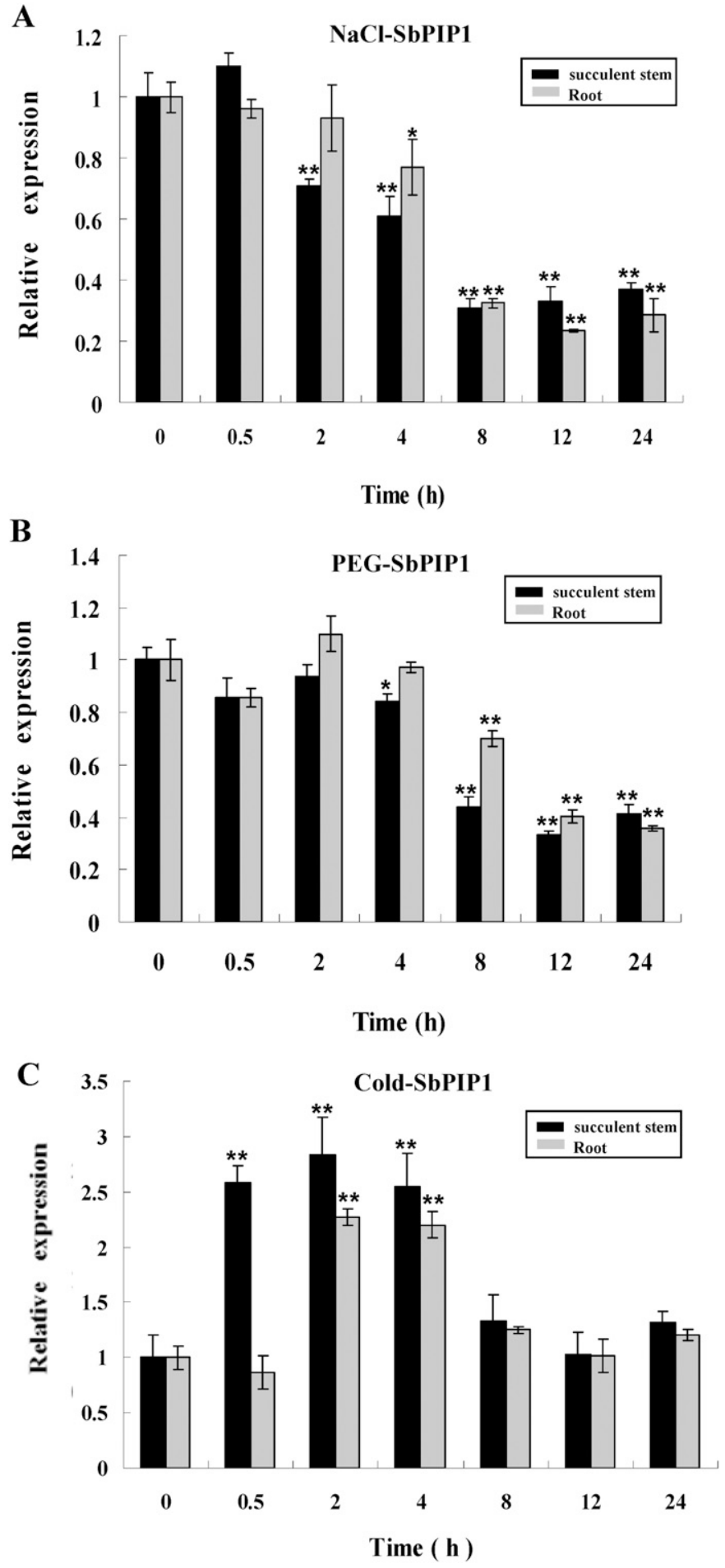

Fig. 4. Quantitative real-time RT-PCR analysis of SbPIP1 expression levels. $(A-C)$ The relative expression of SbPIPI in response to salinity stress $(600 \mathrm{~mm} \mathrm{NaCl})$, dehydration stress [20\% polyethylene glycol 6000 (PEG $6000)]$, and low temperature $\left(4^{\circ} \mathrm{C}\right)$, respectively, for the indicated times. Total RNA was extracted from the roots and succulent stems of 60-d-old seedlings of Salicornia bigelovii in the same position after $0,0.5,2,4,8,12$, and $24 \mathrm{~h}$ of exposure to various stresses. The SbActin mRNA was used as a control to normalize samples. Experiments were repeated three times. Error bars represent the standard errors of three biological replicates of a single treatment. Asterisks indicate significant difference between control and treatment $(*=P<0.05, * *=P<0.01)$. 
confirmed that abiotic stress had a strong influence on AQP gene expression (Gao et al., 2010; Sade et al., 2010; Santos and Mazzafera, 2013; Yue et al., 2014). In this study, we examined the relative mRNA abundance of SbPIP1 after the short-term treatment of $S$. bigelovii seedlings with $\mathrm{NaCl}, \mathrm{PEG}$ 6000, and low temperature. As shown in Fig. 4A, the expression of SbPIP1 was suppressed in succulent stems and roots after salinity stress, and the lowest expression level of SbPIP1 in succulent stems or roots was observed when $S$. bigelovii seedlings were treated with $\mathrm{NaCl}$ for $8 \mathrm{~h}(0.34$-fold) or for $12 \mathrm{~h}$ (0.26-fold), respectively. To monitor the expression patterns of SbPIP1 under drought stress, 20\% PEG 6000 was used to mimic drought treatment. SbPIPl expression in succulent stems began to decrease after PEG treatment and reached its minimum at $12 \mathrm{~h}$ (0.32-fold) (Fig. 4B). Similarly, PEG treatment suppressed the expression of SbPIPl in roots and at $24 \mathrm{~h}$ the transcript level of SbPIP 1 reached its minimum (0.36-fold) (Fig. 4B). The expression patterns of SbPIP1 under $\mathrm{PEG}$ treatment were similar with $\mathrm{NaCl}$ treatment, which is consistent with the reports that regulation of AQP genes in response to drought and cation stresses was similar (Alexandersson et al., 2005; Maathuis et al., 2003). The drastically decreased expression of SbPIP1 in roots and succulent stems of $S$. bigelovii after salt and drought stresses can be considered a negative effect induced by the stress treatments, contributing to weaken membrane water permeability, reduce water transportation, and protect $S$. bigelovii from excessive water loss.

Under cold stress $\left(4{ }^{\circ} \mathrm{C}\right)$ treatment, the expression level of SbPIP1 in succulent stems increased significantly at $0.5 \mathrm{~h}$ and reached the highest expression at $2 \mathrm{~h}$ (2.8fold) and then began to decrease and reach untreated level during 8-24 h (Fig. 4C). On the whole, SbPIP1 expression in roots under cold treatment was similar to that in succulent stems except at $0.5 \mathrm{~h}$ (Fig. 4C). The response of $S b P I P 1$ to cold might be driven partly by cellular water movement. Jang et al. (2007) reported that transgenic $A$. thaliana plants which overexpressed PIP1;4 or PIP2;5 showed increased water flow and so more germination under cold stress. Other research groups have also reported that overexpression of PIPs enhanced the tolerance of plants to low-temperature stress ( $\mathrm{Li}$ et al., 2008; Matsumoto et al., 2009; Yu et al., 2006).

Subcellular localization OF SbPIP1 PROTEIN. To determine the cellular localization of SbPIP1, the ORF of the SbPIP1 was fused in frame with the C-terminal of $G F P$ of pXDG-vector to create a GFP-SbPIP1 fusion construct $\mathrm{pXDG}-\mathrm{GFP}-\mathrm{SbPIP} 1$. The pXDG-vector was used as a negative control. The transient expression of the two constructs in onion epidermal cells was performed by particle bombardment. We observed that green fluorescence from the control GFP protein was uniformly distributed throughout cells (Fig. 5A-C), whereas GFP fluorescence from GFP::SbPIP1 fusion protein was exclusively confined to the represents $50 \mu \mathrm{m}$. Y13, respectively). plasma membrane of onion epidermal cells (Fig. 5D-F). The results suggested that SbPIP1 was a plasma membrane protein, which was consistent with our prediction by using SignalP 3.0 Server.

GENERATION OF TRANSGENIC TOBACCO OVEREXPRESSING $S_{\boldsymbol{B}} \boldsymbol{P I P 1}$. To evaluate the role of SbPIP1 in drought stress, transgenic tobacco plants overexpressing $S b P I P 1$ under the control of CaMV $35 \mathrm{~S}$ promoter were generated, and 10 positive transgenic lines $\left(T_{1}\right)$ were selected by resistance to $\mathrm{Km}$ and confirmed by PCR using Genomic DNA from leaves as templates (Fig. 6). PCR-positive transgenic plants were used for semiquantitative RT-RCR analysis. As shown in Fig. 7, SbPIP1 mRNA could be detected in all PCR-positive tobacco plants, and Y8 showed the highest expression level. No SbPIP1 mRNA was detected in the WT tobacco plants. Among the $\mathrm{T}_{1}$ lines, two lines (Y6 and Y8) were segregated at a rate of 3:1 for kanamycin resistance. Moreover, the two independent transgenic $\mathrm{T}_{2}$ line seedlings survived on $\mathrm{MS}$ medium containing $200 \mathrm{mg} \cdot \mathrm{L}^{-1} \mathrm{Km}$. SbPIP1 expression in the two $\mathrm{T}_{2}$ lines was investigated by semiquantitative RT-PCR. The results showed that $S b P I P 1$ mRNA could be detected in the two transgenic lines but not in the WT plants, with Y8 showing a higher expression levels than Y6 (Fig. 8A).

Overexpression OF SBPIPI ENHANCES TOLERANCE TO DROUGHT STRESS IN TRANSGENIC TOBACCO PLANTS. For drought tolerance analysis, tobacco seedlings from WT, Y6, and Y8 lines were treated with short-period and long-period drought

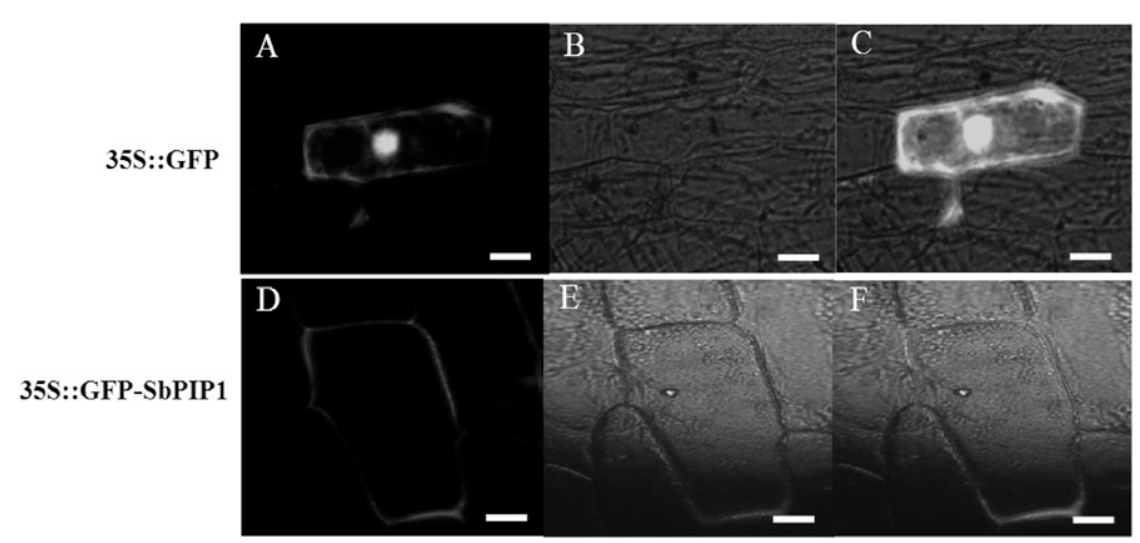

Fig. 5. Subcellular localization of the SbPIP1 protein. A fusion construct expressing GFP::SbPIP1 or a GFP control plasmid was introduced into onion epidermis cells by particle bombardment. The transformed cells were cultured on Murishige and Skoog medium at $25^{\circ} \mathrm{C}$ for $16-24 \mathrm{~h}$ and observed under a confocal microscope. Photographs were taken under dark field for green fluorescence (A and D), in bright light for morphology of the cells $(\mathbf{B}$ and $\mathbf{E})$, and in combination $(\mathbf{C}$ and $\mathbf{F})$. The scale bar

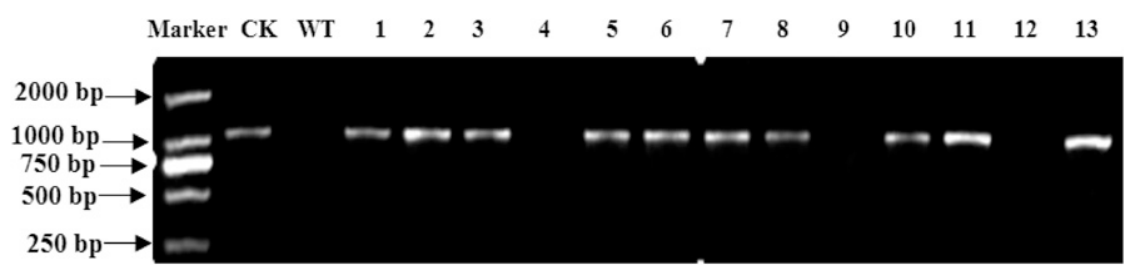

Fig. 6. PCR identification of transgenic tobacco plants. Marker $=2-\mathrm{kb}$ marker, $\mathrm{CK}=$ pCAMBIA2301SbPIP1 plasmid DNA as positive control, WT = genomic DNA from nontransgenic plants as templates, $1-13=$ genomic DNA from transgenic plants $\mathrm{Y} 1-\mathrm{Y} 13$ as templates $(1-13$ represent $\mathrm{Y} 1-$ 


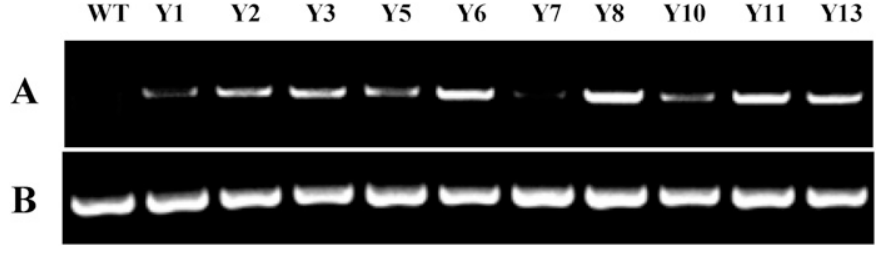

Fig. 7. Semiquantitative RT-PCR analysis of transcript levels of SbPIP1 in different transgenic tobacco plants. (A) The quantity of RT-PCR products of the SbPIPI gene from mRNA of PCR-positive transgenic tobacco plants (Y1-Y3, Y5-Y8, Y10-Y11, and Y13) and WT tobacco plants as templates. (B) The quantity of RT-PCR products of Actin gene from mRNA of PCR-positive transgenic tobacco plants and WT tobacco plants as templates.

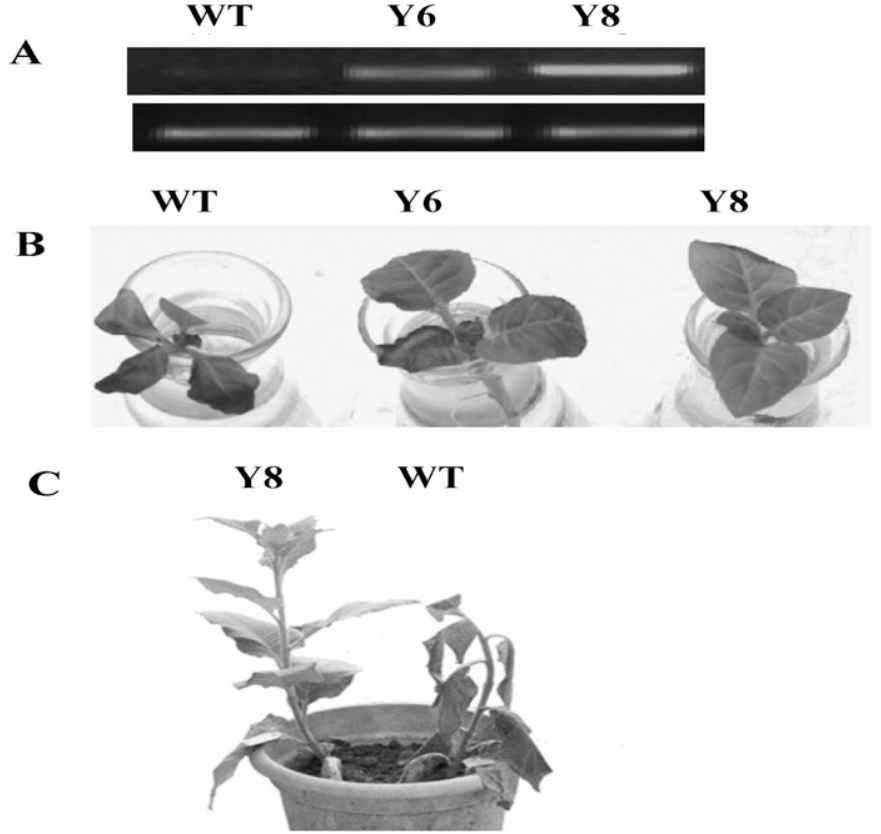

Fig. 8. Drought resistance assay on transgenic tobacco plants at the whole-plant level. The wild-type (WT) and transgenic tobacco (Y6 and Y8) plants at fourleaf stage were cultured in 1/2 Hoagland nutrient solution under a 16/8 h light/ dark cycle at $25^{\circ} \mathrm{C}$ for $10 \mathrm{~d}$, and then some plants were transplanted in fresh $1 / 2$ Hoagland nutrient solution or $1 / 2$ Hoagland nutrient solution containing $20 \%$ polyethylene glycol 6000 (PEG 6000) for $3 \mathrm{~d}$; the other plants were transplanted to containers filled with a mixture of soil and sand (3:1) where they were regularly watered for $30 \mathrm{~d}$ and then deprived of water for $10 \mathrm{~d}$, and the photos were taken. (A) The leaves from Y6, Y8, and WT tobacco plants were used to extract RNA to detect $S b P I P 1$ expression by semiquantitative RT-PCR with NtActin as an internal control. (B) Four-leaf-stage seedlings of Y6, Y8, and WT tobacco were in 1/2 Hoagland nutrient solution containing $20 \%$ PEG 6000 for $3 \mathrm{~d}$, and the photos were taken. (C) Y8 and WT tobacco plants grown in a pot were deprived of water for $10 \mathrm{~d}$ and the photos were taken.

stresses. As shown in Fig. 8B, after being cultured in $1 / 2$ Hoagland nutrient solution containing 20\% PEG 6000 for 3 $\mathrm{d}$, leaf wilting and yellowing was evident in the WT, and the leaves of Y6 plantlets also curled, whereas the leaves of Y8 plantlets still remained expanded. During a long-period drought stress, the WT plants started wilting after $7 \mathrm{~d}$ of water deprivation and became distinctly wilted at the time of 10-d termination of water supply. However, the Y8 tobacco plants still exhibited normal morphology under the same treatment and showed higher tolerance to water stress (Fig. $8 \mathrm{C}$ ), which suggested that the overexpression of SbPIP1 could improve plants' tolerance to drought stress. The results are consistent with previous studies (Cui et al., 2008; Gao et al., 2010; Sade et al., 2010; Zhang et al., 2008). However, some studies also showed that overexpression of some $A Q P$ isoforms increased sensitivity of plants to drought stress (Aharon et al., 2003; Jang et al., 2007). The reason for these contradictory results is not yet clear. The role of $A Q P \mathrm{~s}$ in plant water status under water stress is a complex issue, and specific $A Q P s$ might have specific regulation mechanisms and specific interactions with other molecules. Jang et al. (2007) reported that the expression of an $A Q P$ isoform from $A$. thaliana influenced the transcript levels of other PIP-type $A Q P$ s and $\mathrm{H}+-\mathrm{ATPases}$ of $A$. thaliana, and the integrated regulation resulted in altered water status in transgenic plants under dehydration stress. Different heterologous $A Q P$ s had different interactions with plant endoaquaporins, which might lead to different results when different plants were used as experimental materials (Yu et al., 2005).

OVEREXPRESSION OF SBPIP1 REDUCES THE STABILITY OF PROTOPLASTS OF TRANSGENIC TOBACCO LEAVES IN HYPOTONIC solution. To determine whether SbPIP1 is a functional AQP, water channel activity of the protein in the leaf cells of Y 8 tobacco plants was assayed. When the protoplasts from WT tobacco leaves were put into hypotonic solution, they began to absorb water, but their water absorption rate was slow, and their volume only increased to 1.5 times of the original size after $5 \mathrm{~min}$, and until $30 \mathrm{~min}, 75 \%$ of the protoplasts burst (Fig. 9A-C). The protoplasts from Y8 tobacco leaves absorbed water more quickly in hypotonic solution than those from WT tobacco leaves and expanded to about twice the original size in $1 \mathrm{~min}$, and $75 \%$ of them burst in $5 \mathrm{~min}$ because of excessive expansion (Fig. 9D-F). The results showed that the protein encoded by $S b P I P 1$ was a functional AQP protein and possessed water channel activity. SbPIPl overexpression in transgenic tobacco plants increased their ability of water conductance at the cellular level by increasing the amount of AQP protein in the plasma membrane. Similar results had been reported by other groups (Siefritz et al., 2002; Yu et al., 2005).

OVEREXPRESSION OF $S_{B} P I P 1$ IMPROVES THE RWC AND PROLINE CONTENT AND REDUCES MEMBRANE LIPID PEROXIDATION UNDER DROUGHT STRESS. In comparison with the WT, enhanced drought tolerance in transgenic lines made us investigate differences in their physiology. As shown in Fig. 10A, the RWC was similar in transgenic Y8 line and WT plants under normal conditions. When subjected to water stress caused by different concentrations of PEG, the RWC of the leaves from Y8 and WT plants reduced with the increase of PEG concentrations. Under the treatment of the same concentration of PEG, loss of water in Y8 leaves was less than that of WT. When PEG concentrations were $12 \%, 16 \%$, and $20 \%$, respectively, the RWC difference between Y8 and WT plants reached a significant level (Fig. 10A). Maintaining the ability to retain water is vital for plants to combat drought stress. Studies have shown that the overexpression of $A Q P$ s could enhance the tolerance of plants to abiotic stress by improving hydraulic conductivity, water use efficiency, and retaining better water status (Cui et al., 2008; Lian et al., 2004; Sade et al., 2010; Zhang et al., 2008). $A Q P$ s function in rapid 


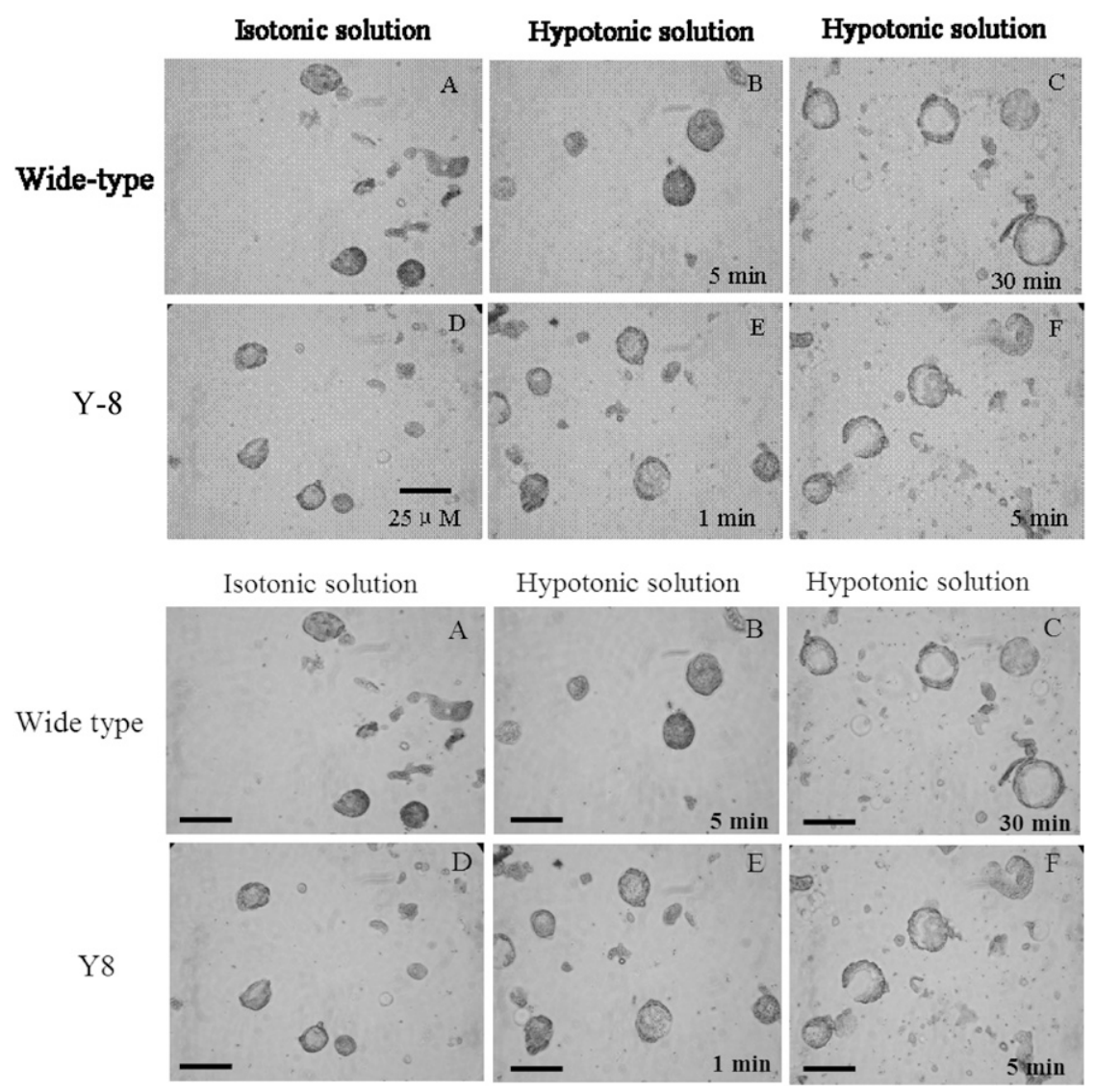

Fig. 9. Responses of protoplasts from wild-type (WT) and transgenic tobacco (Y8) plants to hypotonic solution. W5 (154 mM NaCl, $125 \mathrm{~mm} \mathrm{CaCl}_{2}, 5 \mathrm{~mm} \mathrm{KCl,} 5 \mathrm{~mm}$ Glucose, $\mathrm{pH}$ 5.8) was used as isotonic solution (A and $\mathbf{D})$ and hypotonic solution was prepared by diluting one volume of W5 with two volumes of distilled water $(\mathbf{B}, \mathbf{C}, \mathbf{E}$, and $\mathbf{F})$. When placed in hypotonic solution, protoplasts of WT plant leaves swelled slowly (B), and most of them burst after $30 \mathrm{~min}$ of incubation (C), whereas protoplasts of Y8 plant leaves had a rapid increase in volume in $1 \mathrm{~min}(\mathbf{E})$, and most of them burst in $5 \mathrm{~min}(\mathbf{F})$. The scale bar represents $25 \mu \mathrm{m}$.

transmembrane water flow during growth and development and play important roles in maintaining plant water relations under drought condition. In our study, the contribution of SbPIP1 to cellular water permeability of transgenic tobacco plants was elucidated by protoplast-swelling assay. At the whole plant level, we also observed that SbPIP1-overexpressing plants exhibited a lower rate of water loss compared with WT plants under drought condition, indicating a positive influence of $S b P I P 1$ on water retention.

Drought stress leads to oxidative injury and disruption of osmotic balance. To investigate the function of SbPIPl in these physiological processes, IL, MDA, and proline were quantified in WT and Y8 plants under normal and drought conditions. As shown in Fig. 10B and C, under the treatment of the same concentration of PEG, the IL and MDA contents in the leaves of WT plants were significantly higher than in Y8 leaves, and with the increase of the PEG concentration, the IL and MDA contents in WT plants increased more rapidly than in Y8 plants. Proline measurements displayed a pattern similar to RWC, and compared with WT plants, transgenic plants had higher proline levels under water stress. With the increase of the PEG concentration, the proline content of the leaves of Y8 plants increased faster than that of WT plants and began to reach the level of significant difference when PEG concentration was more than $8 \%$ (Fig. 10B).

Drought stress always induces a rapid accumulation of reactive oxygen species (ROS) and damages the cell membrane by oxidizing proteins, lipids, and DNA (Mittler et al., 2004; Polle, 2001). IL is an indicator of membrane injury. MDA is also the product of lipid peroxidation caused by ROS and can be used to evaluate ROS-mediated injuries in plants (Moore and Roberts, 1998). Compared with WT, SbPIPI overexpression resulted in decreased IL and MDA content, suggesting that the lipid peroxidation caused by ROS damage and membrane injury was relatively alleviated in SbPIPI-overexpressing plants under drought stress. Our findings are consistent with recent reports. Zhou et al. (2012) reported that TaAQP7-overexpressing tobacco plants showed lower levels of MDA and IL when compared with WT plants under drought stress. Overexpression of MaPIP1 in banana (Musa nana) resulted in decreased IL under drought and salt stresses (Xu et al., 2014). The reduced membrane injury conferred by overexpression of SbPIPl may also contribute to improved osmotic adjustment under drought stress. When the plants are exposed to drought stress, they usually accumulate compatible osmolytes to maintain osmotic adjustment. The amino acid proline is one such compatible solute whose accumulation functions to decrease the cellular $\psi_{\mathrm{S}}$ and to enhance cellular protection (Liu and Zhu, 1997). SbPIP1-overexpressing transgenic plants maintained higher levels of proline compared with WT plants when subjected to drought treatment, implying that SbPIP1 may function in maintaining osmotic adjustment under drought stress. Yu et al. (2015) reported that overexpression of SbPIP1 in wheat could improve its salt tolerance by the enhancement of antioxidant response, the accumulation of proline, and the biosynthesis of soluble sugar in the early period. Our results showed that the physiological responses of SbPIPI-overexpressing tobacco under drought stress were similar to that of $S b P I P 1$-overexpressing wheat under salt stress.

\section{Conclusion}

A PIP1 subgroup $A Q P$ gene from $S$. bigelovii, SbPIP1, was isolated and characterized. SbPIP1 exhibited high homology to the PIPIs from Chenopodiaceae plants. The expression of $S b P I P 1$ was induced by cold stress, but was suppressed by $\mathrm{NaCl}$ and PEG. SbPIP1 was localized in the plasma membrane. The overexpression of SbPIP1 resulted in enhanced tolerance to drought stress not only by reducing membrane injury but also maintaining osmotic balance and better water status.

These conclusions obtained from heterologous expression of SbPIP1 in tobacco are valid for such a heterologous system, but 

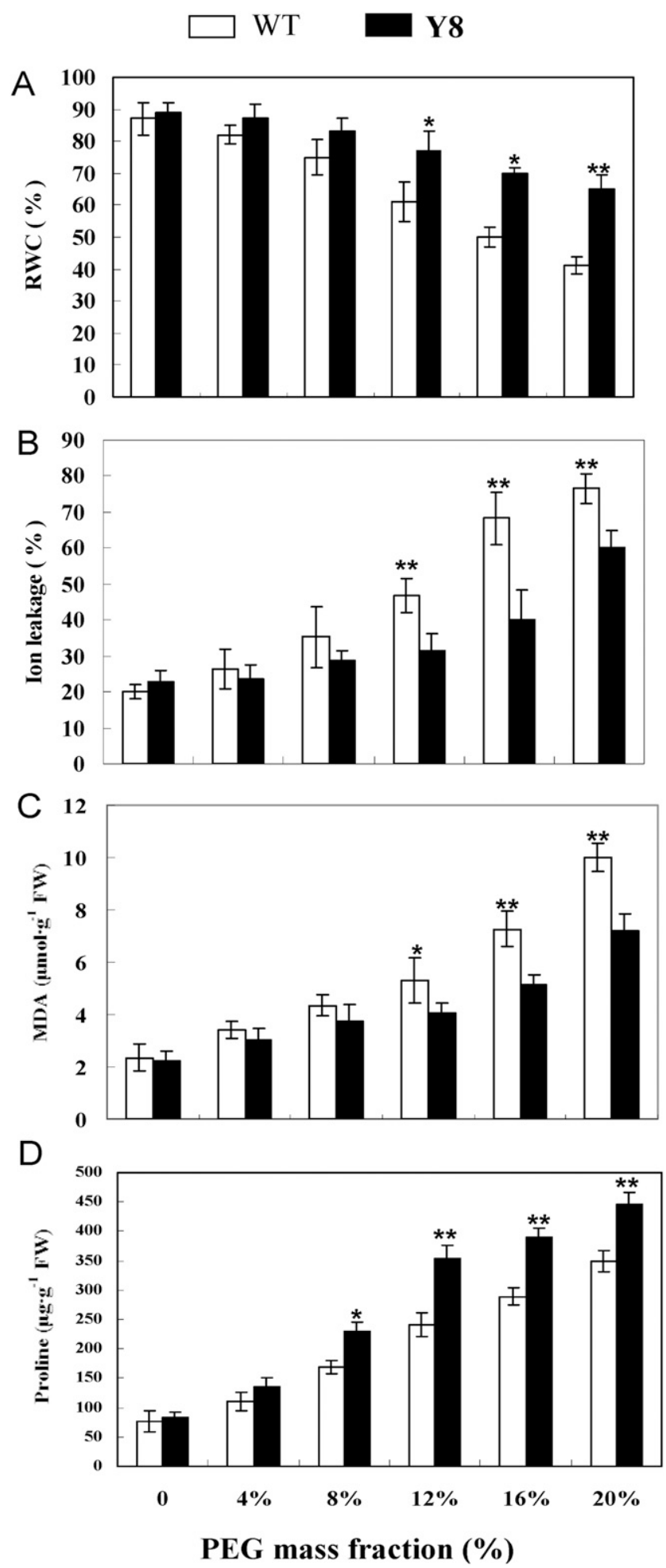

Fig. 10. Analysis of relative water content (RWC), ione leakage (IL), malondialdehyde (MDA), and proline in wild-type (WT) and transgenic line Y8 under drought stress. The WT and Y8 plants with four-leaf stage were transplanted in $1 / 2$ Hoagland nutrient solution under a 16/8 h light/dark cycle at $25{ }^{\circ} \mathrm{C}$ for $10 \mathrm{~d}$, and then the plants were transferred into $1 / 2$ Hoagland nutrient solutions containing $0,4 \%, 8 \%, 12 \%, 16 \%$, and $20 \%$ polyethylene glycol 6000 (PEG 6000), respectively, for $36 \mathrm{~h}$. Tobacco leaves were sampled from WT and Y8 plants under water stress to detect the content of RWC (A), IL (B), MDA (C), and proline (D). Vertical bars indicate \pm sD calculated from four replicates. Asterisks indicate significant difference between the WT and the Y8 line $(*=P<0.05, * *=P<0.01)$. Three biological experiments were performed, which produced similar results. may not be in other plants. Therefore, further studies are required to characterize the function of SbPIP1 in S. bigelovii.

\section{Literature Cited}

Aharon, R., Y. Shahak, S. Wininger, R. Bendov, Y. Kapulnik, and G. Galili. 2003. Overexpression of a plasma membrane aquaporin in transgenic tobacco improves plant vigor under favorable growth conditions but not under drought or salt stress. Plant Cell 15:439-447.

Alexandersson, E., J.A. Danielson, J. Råde, V.K. Moparthi, M. Fontes, P. Kjellbom, and U. Johanson. 2010. Transcriptional regulation of aquaporins in accessions of Arabidopsis in response to drought stress. Plant J. 61:650-660.

Alexandersson, E., L. Fraysse, S. Sjövall-Larsen, S. Gustavsson, M. Fellert, M. Karlsson, U. Johanson, and P. Kjellbom. 2005. Whole gene family expression and drought stress regulation of aquaporins. Plant Mol. Biol. 59:469-484.

Amodeo, G., R. Dorr, A. Vallejo, M. Stuka, and M. Parisi. 1999. Radial and axial water transport in the sugar beet storage root. J. Expt. Bot. 50:509-516.

Ayala, F. and J.W. O'leary. 1995. Growth and physiology of Salicornia bigelovii Torr. at suboptimal salinity. Intl. J. Plant Sci. 156:197-205.

Barrs, H.D. and P.E. Weatherley. 1962. A reexamination of the relative turgidity technique for estimating water deficit in leaves. Austral. J. Biol. Sci. 15:413-428.

Bendtsen, J.D., H. Nielsen, G. von Heijne, and S. Brunak. 2004. Improved prediction of signal peptides: SignalP 3.0. J. Mol. Biol. 340:783-795.

Biasini, M., S. Bienert, A. Waterhouse, K. Arnold, G. Studer, T. Schmidt, F. Kiefer, T.G. Cassarino, M. Bertoni, L. Bordoli, and T. Schwede. 2014. SWISS-MODEL: Modelling protein tertiary and quaternary structure using evolutionary information. Nucleic Acids Res. 42:W252-W258.

Chang, W., X. Liu, J. Zhu, W. Fan, and Z. Zhang. 2016. An aquaporin gene from halophyte Sesuvium portulacastrum, $S p A Q P 1$, increases salt tolerance in transgenic tobacco. Plant Cell Rpt. 35:385-395.

Chaumont, F., F. Barrieu, R. Jung, and M.J. Chrispeels. 2000. Plasma membrane intrinsic proteins from maize cluster in two sequence subgroups with differential aquaporin activity. Plant Physiol. 122:1025-1034.

Chaumont, F., F. Barrieu, E. Wojcik, M.J. Chrispeels, and R. Jung. 2001. Aquaporins constitute a large and highly divergent protein family in maize. Plant Physiol. 125:1206-1215.

Chaumont, F. and S.D. Tyerman. 2014. Aquaporins: Highly regulated channels controlling plant water relations. Plant Physiol. 164:16001618.

Chen, C.Y., E.I. Wong, L. Vidali, A. Estavillo, P.K. Hepler, H.M. Wu, and A.Y. Cheung. 2002. The regulation of actin organization by actin-depolymerizing factor in elongaing pollen tubes. Plant Cell 14:2175-2190.

Chen, S.B., P. Songkumarn, J.L. Liu, and G.L. Wang. 2009. A versatile zero background T-vector system for gene cloning and functional genomics. Plant Physiol. 150:1111-1121.

Cui, X.H., F.S. Hao, H. Chen, J. Chen, and X.C. Wang. 2008. Expression of the Vicia faba VfPIP1 gene in Arabidopsis thaliana plants improves their drought resistance. J. Plant Res. 121:207214.

Eisenbarth, D.A. and A.R. Weig. 2005. Dynamics of aquaporins and water relationsduring hypocotyl elongation in Ricinus communis L. seedlings. J. Expt. Bot. 417:1831-1842.

Feng, L.T. and L. Weng. 2009. The development and utilization of Salicornia bigelovii. J. Salt Chem. Ind. 38:38-42.

Fetter, K., V. Van Wilder, M. Moshelion, and F. Chaumont. 2004. Interactions between plasma membrane aquaporins modulate their water channel activity. Plant Cell 16:215-228. 
Forrest, K.L. and M. Bhave. 2007. Major intrinsic proteins (MIPs) in plants: A complex gene family with major impacts on plant phenotype. Funct. Integr. Genomics 7:263-289.

Gao, Z.X., X.L. He, B.C. Zhao, C.J. Zhou, Y.Z. Liang, R.C. Ge, Y.Z. Shen, and Z.J. Huang. 2010. Overexpressing a putative aquaporin gene from wheat, TaNIP, enhances salt tolerance in transgenic Arabidopsis. Plant Cell Physiol. 51:767-775.

Guan, F., Q. Wang, M. Wang, Y. Shan, Y. Chen, M. Yin, Y. Zhao, X. Feng, F. Liu, and J. Zhang. 2015. Isolation, identification and cytotoxicity of a new noroleanane-type triterpene saponin from Salicornia bigelovii Torr. Molecules 20:6419-6431.

Gupta, A.B. and R. Sankararamakrishnan. 2009. Genome-wide analysis of major intrinsic proteins in the tree plant Populus trichocarpa: Characterization of XIP subfamily of aquaporins from evolutionary perspective. BMC Plant Biol. 20:134-161.

Heath, R.L. and L. Packer. 1968. Photoperoxidation in isolated chloroplasts. I. Kinetics and stoichiometry of fatty acid peroxidation. Arch. Biochem. Biophys. 125:189-198.

Hofmann, K. 1993. TMbase-A database of membrane spanning proteins segments. Biol. Chem. Hoppe Seyler 374:166.

Horsch, R.B., J.E. Fry, N.L. Hoffmann, D. Eichholtz, S.G. Rogers, and R.T. Fraley. 1985. A simple and general method for transferring genes into plants. Science 227:1229-1231.

Horton, P., K.J. Park, T. Obayashi, N. Fujita, H. Harada, C.J. AdamsCollier, and K. Nakai. 2007. WoLF PSORT: Protein localization predictor. Nucleic Acids Res. 35:W585-W587.

Hu, W., Q. Yuan, Y. Wang, R. Cai, X. Deng, J. Wang, S. Zhou, M. Chen, L. Chen, C. Huang, Z. Ma, G. Yang, and G. He. 2012. Overexpression of a wheat aquaporin gene, TaAQP8, enhances salt stress tolerance in transgenic tobacco. Plant Cell Physiol. 53:2127-2141.

Irigoyen, J.J., D.W. Einerich, and M. Sánchez-Díaz. 1992. Water stress induced changes in concentrations of proline and total soluble sugars in nodulated alfalfa (Medicago sativd) plants. Physiol. Plant. 84:55-60.

Jang, J.Y., S.H. Lee, J.Y. Rhee, G.C. Chung, S.J. Ann, and H. Kang. 2007. Transgenic Arabidopsis and tobacco plants overexpressing an aquaporin respond differently to various abiotic stresses. Plant Mol. Biol. 64:621-632.

Jiang, M. and J. Zhang. 2001. Effect of abscisic acid on active oxygen species, antioxidative defence system and oxidative damage in leaves of maize seedlings. Plant Cell Physiol. 42:1265-1273.

Johanson, U., M. Karlsson, I. Johansson, S. Gustavsson, S. Sjovall, L. Fraysse, A.R. Weig, and P. Kjellbom. 2001. The complete set of genes encoding major intrinsic proteins in Arabidopsis provides a framework for a new nomenclature for major intrinsic proteins in plants. Plant Physiol. 126:1358-1369.

Kaldenhoff, R. and M. Fischer. 2006. Functional aquaporin diversity in plants. Biochim. Biophys. Acta 1758:1134-1141.

Larkin, M.A., G. Blackshields, N.P. Brown, R. Chenna, P.A. McGettigan, H. McWilliam, F. Valentin, I.M. Wallace, A. Wilm, R. Lopez, J.D. Thompson, T.J. Gibson, and D.G. Higgins. 2007. Clustal W and Clustal $X$ version 2.0. Bioinformatics 23:2947-2948.

Li, G.W., M.H. Zhang, W.M. Cai, W.N. Sun, and W.A. Su. 2008. Characterization of OsPIP2;7, a water channel protein in rice. Plant Cell Physiol. 49:1851-1858.

Li, J.T., G. Yu, X.H. Sun, Y.Z. Liu, J.L. Liu, X.H. Zhang, C.G. Jia, and H.Y. Pan. 2015. AcPIP2, a plasma membrane intrinsic protein from halophyte Atriplex canescens, enhances plant growth rate and abiotic stress tolerance when overexpressed in Arabidopsis thaliana. Plant Cell Rpt. 34:1401-1415.

Lian, H.L., X. Yu, Q. Ye, X. Ding, Y. Kitagawa, S.S. Kwak, W.A. Su, and Z.C. Tang. 2004. The role of aquaporin RWC3 in drought avoidance in rice. Plant Cell Physiol. 45:481-489.

Liu, J. and J.K. Zhu. 1997. Proline accumulation and salt-stressinduced gene expression in a salt-hypersensitive mutant of Arabidopsis. Plant Physiol. 114:591-596.

Livak, K.J. and T.D. Schmittgen. 2001. Analysis of relative gene expression data using real-time quantitative PCR and the $2-\mathrm{DDCt}$ method. Methods 25:402-408.
Lopez, D., G. Bronner, N. Brunel, D. Auguin, S. Bourgerie, F. Brignolas, S. Carpin, C. Tournaire-Roux, C. Maurel, B. Fumanal, F. Martin, S. Sakr, P. Label, J.L. Julien, A. Gousset-Dupont, and J.S. Venisse. 2012. Insights into Populus XIP aquaporins: Evolutionary expansion, protein functionality, and environmental regulation. J. Expt. Bot. 63:2217-2230.

Lu, Z.J., R.M. Hodges, C.J. Mota-Urbina, P.L. Gallawa, R. Chaturvedi, and C.N. Hodges. 2001. Nutrient constituents of salicornia (Salicornia bigelovii Torr.): A seawater-irrigated new green vegetable. HortScience 36:484 (Abstr.).

Luu, D.T. and C. Maurel. 2005. Aquaporins in a challenging environment:molecular gears for adjusting plant water status. Plant Cell Environ. 28:85-96.

Maathuis, F.J., V. Filatov, P. Herzyk, G.C. Krijger, K.B. Axelsen, S. Chen, B.J. Green, Y. Li, K.L. Madagan, R. Sánchez-Fernández, B.G. Forde, M.G. Palmgren, P.A. Rea, L.E. Williams, D. Sanders, and A. Amtmann. 2003. Transcriptome analysis of root transporters reveals participation of multiple gene families in the response to cation stress. Plant J. 35:675-692.

Maliga, P., D.F. Klessig, A.R. Cashmore, W. Gruissem, and J.E. Varner. 1995. Methods in plant molecular biology: A laboratory course manual. Cold Spring Harbor Lab. Press, Plainview, NY.

Matsumoto, T., H.L. Lian, W.A. Su, D. Tanaka, C. Liu, I. Iwasaki, and Y. Kitagawa. 2009. Role of the aquaporin PIP1 subfamily in the chilling tolerance of rice. Plant Cell Physiol. 50:216-229.

Maurel, C., J. Reizer, J.I. Schroeder, and M.J. Chrispeels. 1993. The vacuolar membrane protein $\gamma$-TIP creates water specific channels in Xenopus oocytes. EMBO J. 12:2241-2247.

Mittler, R., S. Vanderauwera, M. Gollery, and F. Van Breusegem. 2004. Reactive oxygen gene network of plants. Trends Plant Sci. 9:490-498.

Moore, K. and L.J. Roberts. 1998. Measurement of lipid peroxidation. Free Radic. Res. 28:659-671.

Nicholas, K.B., H.B.J. Nicholas, and D.W.I.I. Deerfield. 1997. GeneDoc: Analysis and visualization of genetic variation. Embnew News 4:14.

Parent, B., C. Hachez, E. Redondo, T. Simonneau, F. Chaumont, and F. Tardieu. 2009. Drought and abscisic acid effects on aquaporin content translate into changes in hydraulic conductivity and leaf growth rate: A trans-scale approach. Plant Physiol. 149: 2000-2012.

Park, W., B.E. Scheffler, P.J. Bauer, and B.T. Campbell. 2010. Identification of the family of aquaporin genes and their expression in upland cotton (Gossypium hirsutum L.). BMC Plant Biol. 10:142158.

Peng, Y.H., R. Arora, G.W. Li, X. Wang, and A. Fessehaie. 2008. Rhododendron catawbiense plasma membrane intrinsic proteins are aquaporins and their overexpression compromises constitutive freezing tolerance and cold acclimation ability of transgenic Arabidopsis plants. Plant Cell Environ. 31:1275-1289.

Polle, A. 2001. Dissection the superoxide dismutase-ascorbate-glutathione pathway by metabolic modeling: Computer analysis as a step towards flux analysis. Plant Physiol. 126:445-462.

Rae, L., N.T. Lao, and T.A. Kavanagh. 2011. Regulation of multiple aquaporin genes in Arabidopsis by a pair of recently duplicated DREB transcription factors. Planta 234:429-444.

Sade, N., M. Gebretsadik, R. Seligmann, A. Schwartz, R. Wallach, and M. Moshelion. 2010. The role of tobacco Aquaporin1 in improving water use efficiency, hydraulic conductivity, and yield production under salt stress. Plant Physiol. 152:245-254.

Sade, N., B.J. Vinocur, A. Diber, A. Shatil, G. Ronen, H. Nissan, R. Wallach, H. Karchi, and M. Moshelion. 2009. Improving plant stress tolerance and yield production: Is the tonoplast aquaporin SlTIP 2;2 a key to isohydric to anisohydric conversion? New Phytol. 181:651-661.

Sakurai, J., F. Ishikawa, T. Yamaguchi, M. Uemura, and M. Maeshima. 2005. Identification of 33 rice aquaporin genes and analysis of their expression and function. Plant Cell Physiol. 46:1568-1577. 
Santos, A.B. and P. Mazzafera. 2013. Aquaporins and the control of the water status in coffee plants. Theor. Expt. Plant Physiol. 25:79-93.

Schaffner, A.R. 1998. Aquaporin function, structure and expression: Are there more surprises to surface in water relations? Planta 204:131-139.

Siefritz, F., M.T. Tyree, C. Lovisolo, A. Schubert, and R. Kaldenhoff. 2002. PIP1 plasma membrane aquaporins in tobacco: From cellular effects to function in plants. Plant Cell 14:869-876.

Tamura, K., D. Peterson, N. Peterson, G. Stecher, M. Nei, and S. Kumar. 2011. MEGA5: Molecular evolutionary genetics analysisusing maximum likelihood, evolutionary distance, and maximumparsimony methods. Mol. Biol. Evol. 28:2731-2739.

Vera-Estrella, R., B.J. Barkla, H.J. Bohnert, and O. Pantoja. 2004. Novel regulation of aquaporins during osmotic stress. Plant Physiol. 135:2318-2329.

Wang, L.Y. and K.F. Zhao. 2004. Effect of $\mathrm{NaCl}$ stress on ion compartmentation, photosynthesis and growth of Salicornia bigelovii Torr. J. Plant Physiol. Mol. Biol. 30:94-98.

Wang, Q.Z., X.F. Liu, Y. Shan, F.Q. Guan, Y. Chen, X.Y. Wang, M. Wang, and X. Feng. 2012. Two new nortriterpenoid saponins from Salicornia bigelovii Torr. and their cytotoxic activity. Fitoterapia 83:742-749.

Wang, X.C. 2010. Osmotic effects of $\mathrm{NaCl}$ on cell hydraulic conductivity of corn roots. Acta Biochim. Biophys. Sin. (Shanghai) 42:351-357.

$\mathrm{Xu}$, Y., W. Hu, J. Liu, J. Zhang, C. Jia, H. Miao, B. Xu, and Z. Jin. 2014. A banana aquaporin gene, MaPIP1; 1, is involved in tolerance to drought and salt stresses. BMC Plant Biol. 14:59.

Yu, G.H., X. Zhang, and H.X. Ma. 2015. Changes in the physiological parameters of SbPIP1-transformed wheat plants under salt stress. Intl. J. Genomics 2015:384356.
Yu, Q.J., Y.L. Hu, J.F. Li, Q. Wu, and Z.P. Lin. 2005. Sense and antisense expression of plasma membrane aquaporin BnPIP1 from Brassica napus in tobacco and its effects on plant drought resistance. Plant Sci. 169:647-656.

Yu, X., Y.H. Peng, M.H. Zhang, Y.J. Shao, W.A. Su, and Z.C. Tang. 2006. Water relations and an expression analysis of plasma membrane intrinsic proteins in sensitive and tolerant rice during chilling and recovery. Cell Res. 16:599-608.

Yue, C., H. Cao, L. Wang, Y. Zhou, X. Hao, J. Zeng, X. Wang, and Y. Yang. 2014. Molecular cloning and expression analysis of tea plant aquaporin (AQP) gene family. Plant Physiol. Biochem. 83:65-76.

Zelazny, E., J.W. Borst, M. Muylaert, H. Batoko, M.A. Hemminga, and F. Chaumont. 2007. FRET imaging in living maize cells reveals that plasma membraneaquaporins interact to regulate their subcellular localization. Proc. Natl. Acad. Sci. USA 104:12359-12364.

Zelazny, E., U. Miecielica, J.W. Borst, M.A. Hemminga, and F. Chaumont. 2009. An N-terminal diacidic motif is required for the trafficking of maize aquaporins ZmPIP2;4 and ZmPIP2;5 to the plasma membrane. Plant J. 57:346-355.

Zhang, J.F., Z.Y. Deng, S.H. Cao, X.P. Wang, A.M. Zhang, and X.Q. Zhang. 2008. Isolation of six novel aquaporin genes from Triticum aestivum L. and functional analysis of TaAQP6 in water redistribution. Plant Mol. Biol. Rpt. 26:32-45.

Zhao, Z.Z., Q.Q. Rong, H.N. Liu, Q. Lu, and Z.H. Lu. 2013. Research progress on tolerance mechanisms of typical halophytic vegetation of Salicornia Bigelovii Torr. J. Binzhou Univ. 29:42-46.

Zhou, S., W. Hu, X. Deng, Z. Ma, L. Chen, C. Huang, C. Wang, J. Wang, Y. He, G. Yang, and G. He. 2012. Overexpression of the wheat aquaporin gene, TaAQP7, enhances drought tolerance in transgenic tobacco. PLoS One 7:e52439. 